Karolina Novinšćak

\title{
Auf den Spuren von Brandts Ostpolitik und Titos Sonderweg: deutsch-jugoslawische Migrations- beziehungen in den 1960er und 1970er Jahren
}

Man hatte in der Bundesrepublik bereits Erfahrung mit der Inszenierung des Empfangs von „Gastarbeiter-Jubilaren“ auf deutschen Bahnhöfen ${ }^{1}$, als am 5. August 1970 der 32-jährige Kroate Zvonimir Kanjir in Stuttgart als „500000 Gastarbeiter“ Baden-Württembergs öffentlich begrüßt wurde. ${ }^{2}$ In den Jahren zuvor waren bereits Armando Rodrigues de Sá (1964) aus Portugal und Ismail Bahadir (1969) aus der Türkei bei ihrer Ankunft in der Bundesrepublik Deutschland durch ein offizielles Empfangskomitee medienwirksam als „millionste Gastarbeiter" in Szene gesetzt worden. Kanjir war allerdings der erste Arbeitnehmer aus der Sozialistischen Föderativen Republik Jugoslawien (im Folgenden Jugoslawien) - deren Arbeitsmigranten inzwischen zur größten „Gastarbeiter“- und Ausländergruppe der Bundesrepublik aufgerückt waren -, dem diese Ehre zuteil wurde. Das Begrüßungsgeschenk von Kanjir fiel etwas kleiner aus als in den Jahren zuvor. Während Rodrigues de Sá ein Moped und Bahadir ein Fernsehgerät geschenkt bekamen, musste sich Kanjir mit einem handlichen Kofferradio begnügen, über das er sich damals offensichtlich dennoch sehr gefreut hat. Zwei Jahre später, im Jahr 1972, als endlich auch weibliche ausländische Arbeitskräfte Würdigungen erfuhren, wurde eine junge Frau aus Jugoslawien, die 19-jährige Vera Rimski aus Novi Sad, ausgewählt. Politiker und Presse empfingen sie am Münchener Hauptbahnhof als „zweimillionste Jubiläumsgastarbeiterin“ mit Blumen und Sekt. Der Präsident der Bundesanstalt für Arbeit, Josef Stingl, überreichte ihr als Begrüßungsgeschenk ein tragbares Fernsehgerät und sprach dazu seine Hoffnung aus, sie könne damit vielleicht etwas leichter in die Geheimnisse der schwierigen deutschen Sprache eindringen. ${ }^{3}$

Ob beabsichtigt oder unbeabsichtigt wohnt beiden Begrüßungsgeschenken ein Symbolcharakter inne. Das tragbare Kofferradio und das tragbare Fernsehgerät stehen für Mobilität - der Nutzung und des Nutzers. Die flexiblen Arbeitskräfte aus Jugoslawien wurden während der deutsch-jugoslawischen Anwerbeära (1968-1973) wegen ihrer großen Fähigkeit und Bereitschaft zur Integration in den deutschen Arbeitsmarkt sehr geschätzt ${ }^{4}-$ freilich ohne dass sie die Intention hatten, sich dauerhaft niederzulassen. Die tragbaren Geräte erscheinen als perfekte Willkommensgeschenke für Arbeitskräfte, deren Arbeitsaufenthalte als zeitlich begrenzt und deren Bereitschaft zur Rückkehr in das Land, aus dem sie gekommen waren, als selbstverständlich angenommen wurde. Tatsächlich sind sowohl Vera Rimski als auch Zvonimir Kanjir in ihre Heimat zurückgekehrt: Rimski noch als junge Frau und Kanjir 1989 als kranker Mann mit einer Invalidenrente. Als „Jubiläumsgastarbeiter“ erscheinen beide nun wieder als Erinnerungsikonen einer jugoslawischen Migrationsgeschichte oder deutschen Einwanderungsgeschichte in Ausstellungen, in einschlägigen Studien oder als Titelbilder auf wissenschaftlichen Büchern. ${ }^{5}$

\footnotetext{
${ }^{1}$ Siehe http://www.angekommen.com/iberer/Mio/millionster.html (24.10.2010).

${ }^{2}$ Karl-Heinz Meier-Braun/Reinhold Weber, Kleine Geschichte der Ein- und Auswanderung in BadenWürttemberg, Stuttgart 2009, S.137f.

${ }^{3}$ Süddeutsche Zeitung, 9.3.1972, Großer Bahnhof für Vera Rimski aus Novi Sad.

${ }^{4}$ Vgl. Dokumentarfilm „Sonderzüge - Special trains - Specijalni vlakovi“, Regie: Krsto Papić, Zagreb Film 1971.

${ }^{5}$ Meike Fischer/Monika Heinemann/Karolina Novinšćak u.a. (Hrsg.), ZwischenWelten. Migration aus Osteuropa nach München im 20.Jahrhundert. Ausstellungskatalog, München 2007, S.79; Rüdiger Rossig, Ex-Jugos. Junge MigrantInnen aus Jugoslawien und seinen Nachfolgestaaten in Deutschland, Berlin 2008, S.12; Ulf Brunnbauer (Hrsg.), Transnational Societies, Transterritorial Politics. Migrations
} 
Die meisten Arbeitsmigranten aus dem ehemaligen Jugoslawien blieben jedoch in Deutschland. Fasst man die 915200 Menschen mit Staatsangehörigkeiten der Nachfolgerepubliken des ehemaligen Jugoslawien zusammen, so bilden sie nach den türkischen Staatsbürgern die derzeit zweitgrößte Ausländergruppe der Bundesrepublik Deutschland. ${ }^{6} \mathrm{Da}$ sie seit der Auflösung Jugoslawiens nicht mehr als „Jugoslawen“, sondern nach den einzelnen Staatsbürgerschaften der Nachfolgerepubliken statistisch erfasst werden, fallen sie als quantitativ bedeutsame Migrantengruppe kaum mehr ins Auge. Trotz des nunmehr 20 Jahre zurückliegenden Staatszerfalls Jugoslawiens greifen deutsche Integrations-Studien auf die Kategorie „ehemaliges Jugoslawien“ zurück, ohne dabei eine Differenzierung nach den einzelnen Staatsbürgerschaften vorzunehmen. ${ }^{7}$ Dies hat zur Folge, dass die sehr unterschiedlichen Integrationserfolge der einzelnen Nationalitätengruppen aus dem ehemaligen Jugoslawien zum Beispiel in den Nachweisen der amtlichen Bildungsstatistik ${ }^{8}$ nicht berücksichtigt sind. Damit wird weder der kulturellen Heterogenität der „Ex-Jugoslawen“ noch den unterschiedlichen Migrations- und Integrationskontexten der Kriegsflüchtlinge und Arbeitsmigranten sowie der einzelnen Generationen Rechnung getragen.

Während „ehemaliges Jugoslawien“ als soziologische Kategorie insbesondere bei Integrationsstudien als unzureichend deklariert werden muss, sind das historische Jugoslawien respektive der jugoslawische sozialistische Staat für eine Migrationsgeschichte der Aus- und Einwanderung von ehemals ,jugoslawischen“ Arbeitsmigranten ein wichtiger Relevanzrahmen. Denn bis zum Jahr 1991 besaßen die meisten Arbeitsmigranten einen jugoslawischen „roten Pass“, und es war der sozialistische Staat, der gemeinsam mit der Bundesrepublik die Rahmenbedingungen ihrer Migration entwickelte. Der Großteil kam im Zuge der zwischen der Bundesrepublik Deutschland und Jugoslawien vereinbarten Anwerbung jugoslawischer Arbeitskräfte und des Familiennachzugs in den 1950er bis 1970er Jahren nach Deutschland - die durchschnittliche Aufenthaltsdauer zum Beispiel der Slowenen beträgt 30,2 Jahre, die der Kroaten 27,7 Jahre, die der Bosnier 20,6 Jahre und die der Mazedonier 19,7 Jahre. ${ }^{9}$ Die als temporär angenommene Arbeitsmigration hat de facto zu einer langfristigen Auswanderung und damit zu einer dauerhaften Einwanderung der Menschen aus dem ehemaligen Jugoslawien nach Deutschland geführt. Ihre Einwanderungsgeschichte in die Bundesrepublik Deutschland ist damit auch zugleich eine Auswanderungsgeschichte aus dem sozialistischen Jugoslawien.

Im Folgenden werden die wirtschaftlichen und politischen Rahmenbedingungen des deutsch-jugoslawischen Arbeitskräftetransfers und die Schnittmengen der wirtschaftlichen und politischen Interessen beider Länder im zwischenstaatlichen Beziehungsgefüge seit dem Zweiten Weltkrieg mit dem Fokus auf den deutsch-jugoslawischen Anwerbevertrag vom 12. Oktober 1968 thematisiert. Holm Sundhaussen konstatiert, dass die Beziehungen zwischen zwei Staaten mehr oder minder eng miteinander in ein weitreichendes Netz von außen-, sicherheits-, innenpolitischen und ideologischen Interdependenzen verflochten sind. ${ }^{10}$ Eine

in the (Post-) Yugoslav Region $19^{\text {th }}-21^{\text {st }}$ Century, München 2009; Meier-Braun/Weber, Kleine Geschichte der Ein- und Auswanderung.

${ }^{6}$ Statistisches Bundesamt, Bevölkerung und Erwerbstätigkeit. Ausländische Bevölkerung, Fachserie 1, Reihe 2 (2009), Tabelle 3: Ausländische Bevölkerung 2002 bis 2009, S.33.

${ }^{7}$ Berlin-Institut für Bevölkerung und Entwicklung (Hrsg.), Ungenutzte Potenziale. Zur Lage der Integration in Deutschland, Berlin 2009.

${ }^{8}$ Bundesamt für Migration und Flüchtlinge (Hrsg.), Integrationsreport Teil 1. Schulische Bildung von Migranten, Working Paper 13, Nürnberg 2008.

${ }^{9}$ Bundesamt für Migration und Flüchtlinge (Hrsg.), Ausländerzahlen 2009, Nürnberg 2009, Tabelle 6: Aufenthaltsdauer der ausländischen Bevölkerung nach Staatsangehörigkeit am 31.12.2009, S.14.

${ }^{10}$ Holm Sundhaussen, Jugoslawisch-Deutsche Beziehungen zwischen Normalisierung, Bruch und erneuter Normalisierung, in: Othmar Nikola Haberl/Hans Hecker (Hrsg.), Unfertige Nachbar- 
solche Komplexität gilt für das Beziehungsgefüge im Bereich der deutsch-jugoslawischen Arbeitsmigration. Bereits 1974 hoben Reinhard Lohrmann und Klaus Manfrass in einem von ihnen herausgegebenen Sammelband zur Analyse transnationaler Sozialprozesse hervor, dass sich die Arbeitswanderung auf beiden Seiten, im Aufnahme- und im Herkunftsland, vielfältig auswirkt, diese „durch das Medium der wandernden Menschen miteinander verknüpft" sind und damit gleichzeitig zwischenstaatliche und zwischengesellschaftliche Beziehungen berührt werden. ${ }^{11}$

Die bereits vorliegenden Arbeiten zu Hintergründen und Bedeutung des deutsch-jugoslawischen Anwerbeabkommens innerhalb der neuen Ostpolitik von Bundesaußenminister Willy Brandt basieren weitestgehend auf Quellenmaterial bundesdeutscher Archive. ${ }^{12}$ Der vorliegende Beitrag zur Geschichte der deutsch-jugoslawischen Arbeitsmigration schaut über den nationalen Container hinaus und nimmt eine transnationale Forschungsperspektive ein, die die jeweiligen Nationalstaaten und ihre Migrationspolitiken als Relevanzrahmen nicht in Frage stellt, jedoch auch das Geflecht der gegenseitigen Einflüsse, Bindungen und Abhängigkeiten in den jeweiligen nationalen Arbeitsmigrationspolitiken der Anwerbevertragspartner berücksichtigt. ${ }^{13}$ Im Folgenden werden die Perspektiven beider Staaten, der Bundesrepublik und Jugoslawiens, in der Anwerbephase und das zwischenstaatliche Beziehungsgeflecht vor und während der Verhandlungen über den Anwerbevertrag im Kontext ihrer bilateralen politischen und ökonomischen Beziehungen herausgearbeitet. Die Untersuchung basiert folglich unter anderem auf Quellenmaterial der bundesdeutschen und der jugoslawischen/kroatischen Archive.

\section{Auf Titos Sonderweg: Jugoslawischer Arbeitskräftetransfer in die Bundesrepublik Deutschland}

Nach offiziellen jugoslawischen Angaben verloren 1,7 Millionen Menschen in Jugoslawien während des Zweiten Weltkriegs ihr Leben. Die Kommunistische Partei beklagte gar den Verlust von etwa 75 Prozent ihrer ursprünglichen Mitglieder. ${ }^{14}$ Im Kampf gegen die deutsche Wehrmacht, kroatische Ustašas, serbische Četniks und slowenische Heimatgardisten gingen die Partisanen unter der Führung Titos als Sieger hervor und kultivierten im Rahmen der kollektiven Erinnerung das Feindbild Nummer eins - den „deutschen Faschisten“ mit seinen „Kollaborateuren“. Hingegen galt auf bundesdeutscher Seite „der Kommunist“ angesichts der Teilung Deutschlands und des Kalten Kriegs als das Schreckgespenst der westlichen Zivilisation. In den ersten Jahren der Machtkonsolidierung der Kommunistischen Partei

schaften. Die Staaten Osteuropas und die Bundesrepublik Deutschland, Essen 1989, S.133-151, hier S.133.

${ }^{11}$ Reinhard Lohrmann/Klaus Manfrass, Vorwort, in: dies. (Hrsg.), Ausländerbeschäftigung und internationale Politik, München 1974, S.13.

${ }^{12}$ Karen Schönwälder, Einwanderung und ethnische Pluralität. Politische Entscheidungen und öffentliche Debatten in Großbritannien und der Bundesrepublik von den 1950er bis zu den 1970er Jahren, Essen 2001, S.343f., 365; Monika Mattes, „Gastarbeiterinnen“ in der Bundesrepublik. Anwerbepolitik, Migration und Geschlecht in den 50er bis 70er Jahren, Frankfurt a.M. 2005, S.53; Senad Hadžić, Titos „Gastarbeiter“. Hintergründe und Ursachen des Anwerbeabkommens zwischen der Bundesrepublik Deutschland und Jugoslawien, in: Dietmar Neutatz/Volker Zimmermann (Hrsg.), Die Deutschen und das östliche Europa, Essen 2006, S.103-114; Heike Knortz, Diplomatische Tauschgeschäfte. „Gastarbeiter“ in der westdeutschen Diplomatie und Beschäftigungspolitik 19531973, Köln 2008, S. 140-152.

${ }^{13}$ Vgl. Karolina Novinšćak, The Recruiting and Sending of Yugoslav „Gastarbeiter“ to Germany: Between Socialist Demands and Economic Needs, in: Brunnbauer (Hrsg.), Transnational Societies, S.121-143.

${ }^{14}$ Marie-Janine Calic, Geschichte Jugoslawiens im 20.Jahrhundert, München 2010, S.169. 
Jugoslawiens waren zwischenstaatliche deutsch-jugoslawische Beziehungen zunächst nicht vorstellbar. Doch bereits 1948 ermöglichte der Bruch zwischen Tito und Stalin eine Annäherung Jugoslawiens an die westliche Welt. Der jugoslawisch-sozialistische Alleingang und die außenpolitische Position Jugoslawiens außerhalb des Ostblocks wurden von westeuropäischen Staaten und den USA mit großzügigen Krediten belohnt, was auch schrittweise zu einer Verbesserung der deutsch-jugoslawischen Beziehungen führte. ${ }^{15}$

Die ersten zaghaften Schritte einer bilateralen Zusammenarbeit sowie die Anfänge der Arbeitsmigration zwischen Jugoslawien und der Bundesrepublik Deutschland entwickelten sich zunächst auf ökonomischer Ebene. 1950 wurden Wirtschaftsvertretungen in beiden Staaten eingerichtet, die dann zu politischen Missionen und im Jahr darauf zu Botschaften umgewandelt wurden. ${ }^{16} 1952$ folgte ein Abkommen, das den Warenverkehr zwischen der Bundesrepublik und Jugoslawien regelte, und 1956 unterzeichneten beide Staaten eine Vereinbarung über wirtschaftliche Zusammenarbeit. Die Handelsbeziehungen entwickelten sich gut, denn deutsche Importe sowie große Finanzhilfen der Bundesrepublik für Jugoslawien sicherten der regierenden Kommunistischen Partei die rasch in Angriff genommene industrielle Umgestaltung des Agrarlandes. Ihr Ziel war es, den Wiederaufbau und die Industrialisierung des Landes so schnell wie möglich voranzutreiben und damit die zunächst illegale Abwanderung von Arbeitskräften, auch mithilfe einer Vollbeschäftigungspolitik, zum Versiegen zu bringen.

Bereits in den 1960er Jahren erforderten jedoch einschneidende Wirtschaftsreformen, die Einführung des Selbstverwaltungssozialismus und die Öffnung der jugoslawischen Wirtschaft gegenüber dem internationalen Markt, die Aufgabe der bislang praktizierten Vollbeschäftigungspolitik. Die gleichzeitige Schließung unrentabler Unternehmen forderte bald ihren Tribut: Der Arbeitskräftetransfer aus dem landwirtschaftlichen Sektor in den Industrie- und Dienstleistungssektor stockte, und gleichzeitig drängten geburtenstarke Jahrgänge der Landbevölkerung auf den Arbeits- und Wohnungsmarkt. So stieg die Zahl der Arbeitslosen von 1952 bis zum Jahr 1975 um durchschnittlich 11,4 Prozent pro Jahr an. ${ }^{17}$ Gleichzeitig entwickelte der wirtschaftliche Aufschwung in der Bundesrepublik eine Sogwirkung auf die Bevölkerung Jugoslawiens. Waren 1954 erst 1801 Menschen aus Jugoslawien bei deutschen Arbeitsämtern registriert, so stieg ihre Zahl bis 1962 schon auf 23608. ${ }^{18}$

In den 1950er Jahren war die Arbeitsmigration aus Jugoslawien ins „kapitalistische Ausland" grundsätzlich nicht gestattet bzw. durch administrative Maßnahmen sehr erschwert worden - mit dem Argument, dass in der vollbeschäftigten sozialistischen Wirtschaft jede Arbeitskraft gebraucht werde. Anfang der 1960er Jahre, infolge der Verschlechterung der gesamtwirtschaftlichen Lage, wurde die Arbeitsmigration als Entlastungsventil für den durch hohe Arbeitslosigkeit belasteten Arbeitsmarkt erkannt. Außerdem lernte der jugoslawische Staat die volkswirtschaftliche Bedeutung des Rückflusses der Devisen-Spargelder der Arbeitsmigranten zu schätzen. Daraufhin wurde 1962 die Ausreise erleichtert, und jugoslawische Behörden begannen Visa für längere Arbeitsaufenthalte im Ausland auszustellen. ${ }^{19}$ Ein Amnestiegesetz im selben Jahr hob schließlich die in den Vorjahren erfolgte Arbeitsmigration aus der Illegalität und ermöglichte Personen, außer sogenannten Kollabo-

\footnotetext{
${ }^{15}$ Vgl. Sundhaussen, Jugoslawisch-Deutsche Beziehungen, S.134.

${ }^{16}$ Ebenda, S. 135.

${ }^{17}$ Wilfried Künne, Die Außenwanderung jugoslawischer Arbeitskräfte. Ein Beitrag zur Analyse internationaler Arbeitskräftewanderungen, Königstein i.Ts. 1979, S.30.

${ }^{18}$ Ivo Baučić, Socialno-ekonomske posljedice vanjskih migracija radne snage iz Jugoslavije, in: Geografski glasnik 33-34 (1971/72), S.25-59, hier S.27, Tab. II.

${ }_{19}$ Ders., Die Auswirkungen der Arbeitskräftewanderung in Jugoslawien, in: Lohrmann/Manfrass (Hrsg.), Ausländerbeschäftigung, S.171-206, hier S. 195.
} 
rateuren sowie Spionen und Kriegsverbrechern, die seit 1945 illegal die Grenze überschritten hatten, eine Rückkehr oder den Besuch ihrer Heimat. ${ }^{20}$

Die sukzessive Öffnung der Grenzen für jugoslawische Arbeitsmigranten in den 1960er Jahren wurde von einer ideologischen Neuinterpretation des gesellschaftlichen Phänomens der Arbeitsmigration begleitet. Der Arbeitsmigrant galt fortan nicht mehr als „Landesverräter“, sondern als eine Art „Entwicklungshelfer“ im nachholenden Industrialisierungsprozess Jugoslawiens. In den Folgejahren diskutierte der Bund der Kommunisten verstärkt die Möglichkeit der Auslandsbeschäftigung zur Unterstützung seiner Wirtschaftsreformen. Das neue migrationspolitische Credo lautete, dass Arbeitsmigration als Bestandteil der internationalen Arbeitsteilung hinzunehmen sei und eine erfolgreiche Integration der jugoslawischen Wirtschaft in den Weltmarkt die Freiheit zur Zirkulation der Arbeitskräfte einschließen müsse. ${ }^{21}$

Indem ein nicht unerheblicher Teil der jugoslawischen Arbeiterschaft nationale Grenzen überschritt, wurde das nationale Container-Konzept von einer jugoslawischen Arbeiterklasse auf jugoslawischem Boden gesprengt und der sozialistische Staat herausgefordert, eine transnationale Perspektive im Einklang mit seiner Ideologie zu formulieren. Die ideologische Legitimation der jugoslawischen Arbeitsmigration stand und fiel mit der Prämisse, wonach die Arbeitsmigranten nur „vorübergehend“ im Ausland seien und sie trotz ihrer territorialen Entfernung „ein organischer Bestandteil der jugoslawischen Arbeiterklasse“22 blieben. Aus dieser Grundannahme leitete sich in Jugoslawien die offizielle Bezeichnung der Arbeitsmigranten als „temporär im Ausland beschäftigte Arbeiter“ (radnici na privremenom radu u inozemstvu) ab, die auch in Abgrenzung zu dem Begriff Auswanderer (iseljenici) für die Migranten in Übersee und der in Jugoslawien negativ besetzten Bezeichnung Emigrant (emigrant) ${ }^{23}$, der sich auf emigrierte politische Opponenten bezog, formuliert wurde.

Durch gezielte Vermittlung der Arbeitslosen ins Ausland seitens der jugoslawischen Arbeitsverwaltung sowie den Abschluss bilateraler Abkommen zwischen Jugoslawien und westlichen Anwerbestaaten wurde die Arbeitsmigration seit Mitte der 1960er Jahre staatlich forciert. ${ }^{24}$ In den folgenden Jahren schloss die jugoslawische Regierung Anwerbeverträge mit Frankreich und Österreich 1965, mit Schweden 1966, mit der Bundesrepublik Deutschland 1968 und schließlich auch mit Belgien, Luxemburg, den Niederlanden und Australien 1970.

Die Migration der jugoslawischen Arbeitsuchenden entwickelte sich, begünstigt durch den Abschluss des deutsch-jugoslawischen Anwerbevertrages am 12. Oktober 1968, zu einer Massenbewegung. Die Zahl der jugoslawischen Arbeitsmigranten in Europa und in der Bundesrepublik Deutschland wuchs seit den 1960er Jahren stetig, nach dem Anwerbeabkommen sogar rasant und erreichte 1973 mit 860000 Abwanderern ins europäische Ausland ihren Höhepunkt (Schaubild 1). Die Bundesrepublik Deutschland hatte zu diesem Zeitpunkt mit 553500 Arbeitswanderern aus Jugoslawien respektive 62 Prozent den europaweit größten Anteil. Überrepräsentiert waren junge Menschen aus dem Agrarsektor, während Personen mit Gymnasial- oder Universitätsabschluss seltener abwanderten. ${ }^{25}$ Das

\footnotetext{
${ }^{20}$ Archiv der Gegenwart (AdG), Bd.32, 9738/C, 14.3.1962.

${ }^{21}$ Vgl. Othmar Nikola Haberl, Die Abwanderung von Arbeitskräften aus Jugoslawien. Zur Problematik ihrer Auslandsbeschäftigung und Rückführung, München 1978, S.70f.

22 Živan Tanić, Ekonomska emigracija: klasno određenje i svest, in: Sociologija 14 (1972), S.441-457, hier S. 446.

${ }^{23}$ Emil Heršak, Emigrant, in: ders. (Hrsg.), Leksikon migracijskoga i etničkoga nazivlja, Zagreb 1998 , S.53.

${ }^{24}$ Haberl, Die Abwanderung von Arbeitskräften, S. 74-108.

${ }^{25}$ Künne, Die Außenwanderung, S. 136f., $161 \mathrm{f}$.
} 
niedrige Lohnniveau in Jugoslawien veranlasste indes auch viele qualifizierte Arbeiter zur Abwanderung. Aus den Erhebungen der jugoslawischen Volkszählung von 1971 geht hervor, dass 45,6 Prozent der Arbeitsmigranten qualifizierte Arbeitskräfte waren. Den Schwerpunkt der bundesdeutschen Anwerbung jugoslawischer Arbeitnehmer bildeten bis zum Anwerbestopp 1973 die Republik Kroatien und die Republiken Bosnien und Herzegowina, da sich auf diese Regionen viele Anforderungen deutscher Betriebe konzentrierten.

Schaubild 1: Arbeitsmigration aus Jugoslawien nach Europa und in die Bundesrepublik Deutschland im Vergleich zu Arbeitsuchenden und freien Arbeitsplätzen in Jugoslawien 1964-1976

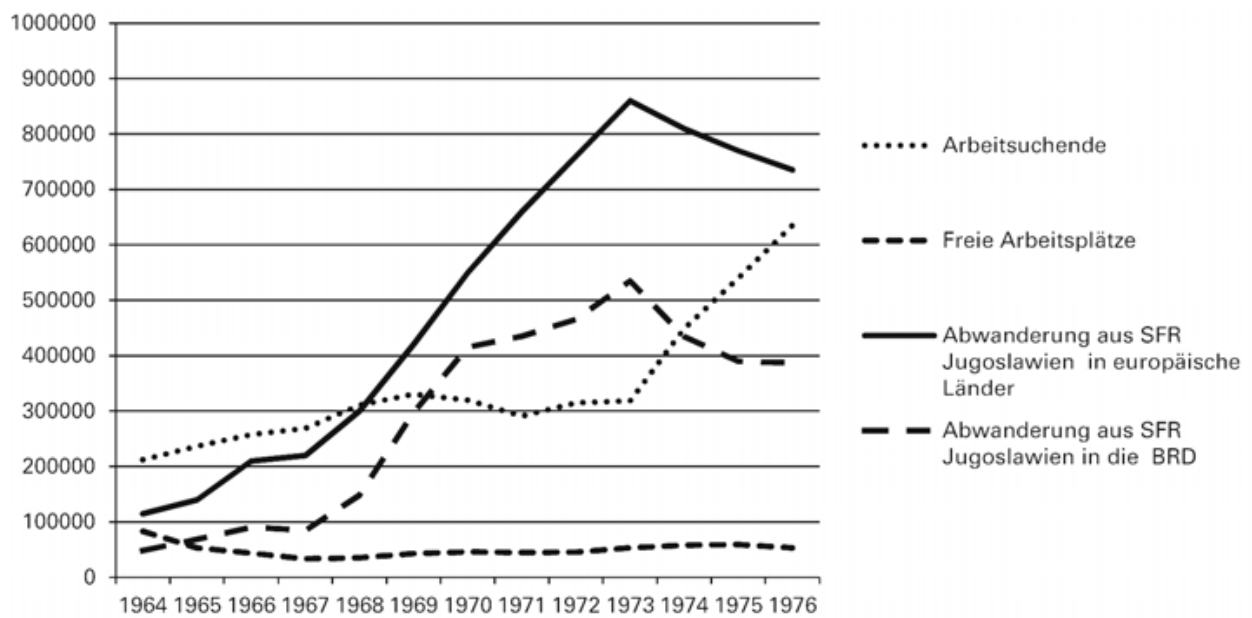

Quelle: Jugoslavija - Statistički godišnjak (Statistisches Jahrbuch), Belgrad, Februar 1989, S. 70, Tab. 4-8.

\section{Arbeitsmigration während der deutsch-jugoslawischen politischen Eiszeit (1957-1967/68)}

Während der oben skizzierten ersten Phase der bilateralen ökonomischen Annäherung und der noch nicht bilateral geregelten, aber stetig steigenden Arbeitsmigration gestalteten sich die politischen Beziehungen zwischen der Bundesrepublik und Jugoslawien schwierig. Die bundesdeutsche Wirtschaftshilfe entsprang dem auch von den Verbündeten verfolgten politischen Interesse, Jugoslawien im westlichen Lager zu halten. Politisch verschlechterten sich die deutsch-jugoslawischen Beziehungen gravierend, als Tito den Alleinvertretungsanspruch der Bundesrepublik immer weiter in Frage stellte. Als Jugoslawien schließlich am 10.Oktober 1957 diplomatische Beziehungen zur Deutschen Demokratischen Republik (DDR) aufnahm, reagierte die westdeutsche Regierung unter Konrad Adenauer prompt und wandte gegen Jugoslawien die Hallstein-Doktrin an, die besagte, dass eine Anerkennung der DDR als „feindlicher Akt“ gegen die Bundesrepublik zu werten sei. Nur neun Tage später wurden die diplomatischen Beziehungen zu Jugoslawien abgebrochen und die außenpolitische Kommunikation lief fortan über konsularische Beziehungen der Schutzvertretungen Frankreich und Schweden.

Trotz der politischen Eiszeit zwischen der Bundesrepublik und Jugoslawien aufgrund der Deutschlandfrage hielt die Arbeitsmigration aus Jugoslawien in die Bundesrepublik nicht nur an, ihr Umfang stieg sogar kontinuierlich. Das Konsulat der Bundesrepublik 
Deutschland in Zagreb meldete dem Auswärtigen Amt im Oktober 1962, dass Tag für Tag rund 200 Arbeiter nach Deutschland abreisten - zur Zufriedenheit der deutschen Industrie:

„Aus zahlreichen hier vorliegenden Äußerungen deutscher Firmen geht hervor, daß die Industrie mit den jugoslawischen Gastarbeitern durchaus zufrieden ist. [...] Die täglichen Schlangen der Arbeitswilligen vor dem deutschen Konsulat, die unter Ordnungsschutz der Polizei stehen, sind zwar als sichtbare Zeichen der Wirtschaftskrise nicht erwünscht, werden jedoch für die beachtlichen Vorteile in Kauf genommen." ${ }^{\prime 26}$

In Jugoslawien war Anfang der 1960er Jahre eine organisierte Anwerbung von Arbeitskräften verboten und auch in der Bundesrepublik konnte aufgrund des Fehlens eines bilateralen Anwerbeabkommens keine staatlich organisierte Werbung für jugoslawische Arbeitskräfte durchgeführt werden. Stattdessen erfolgte die Rekrutierung von Arbeitskräften aus Jugoslawien für die bundesdeutsche Wirtschaft z.B. durch Verwandten- und Bekanntenwerbung, durch jugoslawische Geschäftsfreunde deutscher Firmen, anlässlich deutscher Geschäftsbesuche in Jugoslawien oder durch Abschluss von Werkverträgen mit jugoslawischen Firmen. ${ }^{27}$

Das jugoslawische Arbeits- sowie das Außenministerium beklagten zunehmend ihre fehlenden Einflussmöglichkeiten auf die Arbeitsmigration in die Bundesrepublik. ${ }^{28}$ Daher strebten sie Verhandlungen mit der Bundesrepublik über eine Sozialversicherungskonvention und die Gleichstellung der jugoslawischen Arbeiter mit jenen aus den EWG-Ländern an. Beidem stimmte der Bundesexekutivrat am 29.Juni 1964 zu. Nur einen Monat später kam es in Belgrad zu deutsch-jugoslawischen Sachverständigengesprächen über die Möglichkeit des Abschlusses einer Anwerbevereinbarung und eines Sozialversicherungsabkommens. ${ }^{29}$ Diese wurden im darauffolgenden Jahr fortgeführt, ohne jedoch zu einem Abschluss zu gelangen.

Obwohl die Bundesrepublik bereits mit sechs Staaten Anwerbeabkommen geschlossen hatte, folgte sie in der Anfangsphase der deutsch-jugoslawischen Migrationsbeziehungen nicht dem Wunsch der jugoslawischen Seite nach einer staatlichen Regelung. Die Arbeitsmigrationspolitik der Bundesregierung fußte - neben dem Grundsatz der Abhängigkeit der Ausländerbeschäftigung von der Arbeitsmarktsituation und Wirtschaftslage sowie der grundsätzlichen Ablehnung einer Einwanderungspolitik - auf dem Europäergrundsatz, nach dem Staatsangehörigen außereuropäischer Staaten und von Ostblockstaaten grundsätzlich der Arbeitsaufenthalt nicht zu gestatten sei. ${ }^{30}$ Auch wenn Jugoslawien blockfrei war, blieben die Chancen für ein Abkommen schlecht, da die Bundesrepublik aufgrund der Deutschlandfrage keine freundschaftlichen Beziehungen zu Titos Staat unterhielt.

Die schlechten politischen Beziehungen und das gegenseitige Misstrauen traten insbesondere im Bereich der Arbeitsmigration zutage und spiegelten sich in den Vorgesprächen von 1964 zum Anwerbeabkommen wider. Hier machte die jugoslawische Seite deutlich, dass sie, entgegen den üblichen bundesdeutschen Anwerbeverfahren, eine ständige deutsche Kommission der Bundesanstalt für Arbeit in Jugoslawien nicht dulden würde. Vielmehr wollten die jugoslawischen Behörden die Auswahl der Arbeitsmigranten ausschließlich

\footnotetext{
${ }^{26}$ Bundesarchiv Koblenz (BArch), B 149/6240, Jugoslawische Gastarbeiter. Bericht des Konsulats der Bundesrepublik Deutschland an das Auswärtige Amt, Zagreb, 23.10.1962, S.2f.

${ }^{27}$ Vgl. ebenda, S.3.

${ }^{28}$ Arhiv Jugoslavije, Beograd (AJ), Fond 130/626/1034: Državni sekretarijat za inostrane poslove Saveznom Izvršnom Veću, br. 423534, Beograd, 4.6.1964, Bl.1f.

${ }^{29}$ BArch, B 149/6241, Bericht des Referenten, Regierungsdirektor Dr. Dahnen, Abt. II, IIa 4 - 2430.6: Beschäftigung jugoslawischer Arbeitnehmer in der Bundesrepublik, hier: Sachverständigengespräche in Belgrad vom 21.-24.7.1964, Bonn, 5.8.1964, S.1-5.

${ }^{30}$ Vgl. Reinhard Lohrmann, Politische Auswirkungen auf die Bundesrepublik Deutschland, in: ders./ Manfrass (Hrsg.), Ausländerbeschäftigung, S.103-140, hier S.121f.
} 
selbst durchführen. Außerdem forderte Jugoslawien das Recht, ihre in der Bundesrepublik beschäftigten Arbeitnehmer zurückrufen zu können, und eine Zulassung von Vertretern jugoslawischer gewerkschaftlicher und kultureller Organisationen, „die in Zusammenarbeit mit Vertretern entsprechender deutscher Organisationen die Eingewöhnung jugoslawischer Arbeitnehmer erleichtern und ihre kulturellen und Vergnügungsbedürfnisse organisiert befriedigen" sollten. ${ }^{31}$ Gegen diese in den jugoslawischen Entwurf für eine Anwerbevereinbarung eingebrachten Punkte hatten die bundesdeutschen Sachverständigen erhebliche Bedenken. Ein Rückrufrecht des jugoslawischen Staates gegenüber den Arbeitsmigranten und ein institutionalisierter jugoslawischer Betreuungsdienst auf deutschem Territorium waren für die westdeutsche Seite nicht hinnehmbar, insbesondere

„im Hinblick auf die u. U. entstehenden Reibungen mit den in der Bundesrepublik bereits vorhandenen Exilorganisationen, die sich im allgemeinen bisher in voll befriedigender Weise der Betreuung der hier beschäftigten Jugoslawen - zumeist sind es Kroaten - annehmen“. ${ }^{2}$

Während also eine bilaterale Zusammenarbeit im Bereich der Arbeitsmigration nach 1965 stagnierte, reagierte die Bundesanstalt für Arbeit 1966 mit restriktiven Maßnahmen, um den unkontrollierten Zuzug von ungelernten männlichen Arbeitnehmern aus Jugoslawien zu stoppen. Nach einer Regelung zur Beschäftigung jugoslawischer Arbeitnehmer in deutschen Betrieben sollten grundsätzlich Arbeitskräfte aus den EWG-Staaten und den Anwerbeländern jugoslawischen Arbeitskräften vorgezogen werden.$^{33}$ Eine Arbeitserlaubnis konnte demnach nur Männern aus Jugoslawien mit Fachkenntnissen ausgestellt werden, die aus den anderen Anwerbeländern nicht angeworben werden konnten. Weibliche Arbeitskräfte konnten hingegen weiterhin auch dann rekrutiert werden, wenn sie über keine Fachkenntnisse verfügten.

Während Arbeitsmigranten aus Jugoslawien in der deutschen Wirtschaft gefragt waren, begegneten die bundesdeutschen amtlichen Stellen, die Ausländerpolizei und der Verfassungsschutz einer Arbeitskräfteanwerbung aus einem sozialistischen Staat mit Skepsis. Ulrich Herbert stellt für die 1960er Jahre fest, dass westdeutsche Behörden „außerordentliche Befürchtungen vor einem Import des Kommunismus in Gestalt kommunistischer Arbeiter“34 hatten, und auch Karen Schönwälder beobachtet in ihrer Untersuchung zur Ausländerpolitik für die erste Hälfte der 1960er Jahre eine „panische Kommunistenangst“ der Bundesregierung $^{35}$, die auch das Misstrauen gegenüber Ausländern schürte. „Der Spiegel“ zitierte 1961 Dr. Kurt Sicha, einen für Ausländerfragen zuständigen Referenten im Bundesarbeitsministerium, mit den warnenden Worten: „Wir haben der Bundesanstalt schon 1955 gesagt: ,Holt keine Jugoslawen rein“ “36 Doch trotz der politischen Warnungen vor „kommunistisch infizierten Tito-Arbeitern“"37 beschäftigten deutsche Unternehmen in den 1960er Jahren weiterhin Jugoslawen. Im Jahr 1966 erklärte die Zeitschrift „Der Arbeitgeber“ die hohe Nachfrage nach jugoslawischen Arbeitskräften trotz der Kenntnis, dass „von jugoslawischer Seite auch planmäßig als Arbeitskräfte politische Funktionäre in die BRD geschleust werden, um die hier beschäftigten Jugoslawen in den Griff zu bekommen “38, folgendermaßen:

\footnotetext{
${ }^{31}$ BArch, B 149/6241, Bericht des Referenten, Regierungsdirektor Dr. Dahnen, Abt. II, IIa 4 - 2430.6: Beschäftigung jugoslawischer Arbeitnehmer in der Bundesrepublik, hier: Sachverständigengespräche in Belgrad vom 21.-24.7.1964, Bonn, 5.8.1964, S.4.

32 Ebenda.

${ }^{33}$ Vgl. Rolf Weber, Problematische Jugoslawen, in: Der Arbeitgeber (1966), Nr.21, S.651f., hier S. 652 .

${ }^{34}$ Ulrich Herbert, Geschichte der Ausländerpolitik in Deutschland, München 2001, S.214.

${ }^{35}$ Schönwälder, Einwanderung und ethnische Pluralität, S.281.

36 Treck aus Titos Land, in: Der Spiegel, 27.12.1961, S.21.

37 Ebenda.

${ }^{38}$ Weber, Problematische Jugoslawen, S.652.
} 
„Tatsächlich wird von den deutschen Betrieben, die Jugoslawen beschäftigen, bestätigt, daß die Jugoslawen besonders große Bereitschaft zeigen, sich im Betrieb einzugliedern, daß nahezu keine Anpassungsschwierigkeiten bestehen, die Jugoslawen fleißige und zum großen Teil qualifizierte Arbeitskräfte sind. Vielfach können sich die zumeist aus dem nördlichen Teil Jugoslawiens kommenden Arbeitskräfte auch in deutscher Sprache verständigen. “ ${ }^{39}$

Zugleich formte sich bei den jugoslawischen Machthabern eine panische Angst vor den politischen Emigranten in der Bundesrepublik. Denn viele der ehemaligen Kriegsgegner der Partisanen hatten Zuflucht in der Bundesrepublik gefunden, insbesondere kroatische Ustaša-Anhänger, aber auch gemäßigtere Oppositionelle, die den Alleinherrschaftsanspruch der Kommunistischen Partei in Frage stellten und in Jugoslawien politisch verfolgt wurden. Mit der Öffnung der Grenzen für Arbeitsmigranten fürchtete die jugoslawische Regierung nun einen erneuten Import der anti-jugoslawischen Programmatik der Oppositionellen, die bislang durch das Wiedereinreiseverbot von der Bevölkerung Jugoslawiens ferngehalten werden konnte. Den politischen Handlungsdruck der jugoslawischen Regierung erhöhten insbesondere anti-jugoslawische Aktionen und terroristische Angriffe von meist kroatischen Exilanten in der Bundesrepublik. So kam es unter anderem am 29. November $1962 \mathrm{zu}$ einem Bombenangriff auf die jugoslawische Mission in Bad Godesberg, woraufhin das jugoslawische Außenministerium diesen Angriff als eine der brutalsten anti-jugoslawischen Provokationen, die in der Bundesrepublik begangen worden seien, bezeichnete. ${ }^{40}$ Mit Sorge wurde von den jugoslawischen Behörden zudem zur Kenntnis genommen, dass die Exilanten in der Bundesrepublik als Arbeitsvermittler, Dolmetscher oder Sozialarbeiter in den Kreisen der Arbeitsmigranten auftraten und damit ein neues Wirkungsfeld für ihre anti-jugoslawischen Aktionen erschlossen. ${ }^{41}$ Eine Rekrutierung der Arbeitsmigranten für den politischen Kampf gegen den jugoslawischen Staat war für die Exilanten auch insofern lohnenswert, da die Arbeiter bei ihren Heimreisen z. B. die von den Exilanten verfassten politischen Schriften über die Grenze schmuggeln konnten.

Die mögliche politische Mobilisierung der Arbeitsmigranten lief der selbstauferlegten staatlichen Fürsorgepflicht Titos für den im Ausland weilenden Teil der jugoslawischen Arbeiterklasse zuwider und barg gleichzeitig die Gefahr einer Destabilisierung des Herrschaftsgefüges innerhalb Jugoslawiens. Dem jugoslawischen Staat waren aufgrund der schlechten politischen Beziehungen zur Bundesrepublik gleichsam die Hände gebunden, sodass sie weder gegen die anti-jugoslawischen politischen Aktionen vorgehen noch durch Betreuungsdienste die Arbeitsmigranten an den sozialistischen Heimatstaat binden oder gar überwachen konnten. Die Sorge um die nationale Entfremdung der jugoslawischen Arbeitskräfte und der vermeintlich negative Einfluss der Exilanten ließen eine politische Präsenz des jugoslawischen Staates innerhalb der Migrantengemeinden in der Bundesrepublik umso dringlicher erscheinen. Bereits 1964 empfahl der stellvertretende Staatssekretär für auswärtige Angelegenheiten Marko Nikezić dem regierenden Bundesexekutivrat, einer weiteren anti-jugoslawischen politischen Mobilisierung und Ausbeutung der jugoslawischen Arbeitskräfte durch ein deutsch-jugoslawisches Anwerbeabkommen entgegenzutreten. $^{42}$

Nachdem 1965 auf den jugoslawischen Vizekonsul Andrija Klarić ein Mordanschlag verübt und 1966 Konsul Savo Milanović in Stuttgart von einem Exilanten aus Kroatien ermordet worden war, warf die Regierung Jugoslawiens der Bundesregierung vor, jugosla-

\footnotetext{
${ }^{39}$ Ebenda, S. 651.

${ }^{40}$ Vgl. Archiv der Gegenwart (AdG), Bd.32, 10.271/B, 1.12.1962.

41 AJ 130/626/1034: Državni sekretarijat za inostrane poslove Saveznom Izvršnom Veću, br. 423534, Beograd, 4.6.1964.

${ }^{42}$ Ebenda.
} 
wische Bürger und Diplomaten nicht ausreichend zu schützen. Das jugoslawische Außenministerium interpretierte die Häufung anti-jugoslawischer Aktionen und Angriffe kroatischer Exilanten als eindeutiges politisches Druckmittel der Bundesrepublik gegenüber Jugoslawien, denn zeitlich koinzidierten sie mit Titos Besuch in der DDR und dem Besuch Ulbrichts in Jugoslawien. ${ }^{43}$ Für die jugoslawische Regierung war klar: je schlechter die bilateralen Beziehungen, desto intensiver die anti-jugoslawischen Aktionen innerhalb der Migrantengemeinden der Bundesrepublik. ${ }^{44}$

Zusammenfassend lassen sich die Erwartungen der jugoslawischen Regierung an eine bilaterale Zusammenarbeit im Feld der Arbeitsmigration durch ein Anwerbeabkommen mit der Bundesrepublik in folgende Interessensgebiete einteilen:

1. Soziale Gleichstellung der jugoslawischen Arbeiter mit den anderen ausländischen Arbeitnehmern der Bundesrepublik Deutschland;

2. Maximierung der Arbeitsmigration mit gleichzeitiger Reduzierung der Arbeitslosigkeit;

3. Erhöhung der Devisenrückflüsse durch Spareinlagen, Investitionen und Rentenüberweisungen der Arbeitsmigranten;

4. Staatliche Lenkung und Kontrolle der deutsch-jugoslawischen Arbeitsmigration in Jugoslawien, aber auch auf dem Gebiet der Bundesrepublik Deutschland;

5. Verhinderung politischer Mobilisierung der Arbeitsmigranten durch „Emigranten“;

6. Verstärkung der Bindung der Arbeitsmigranten an das Herkunftsland.

Eine nachhaltige staatliche Einflussnahme Jugoslawiens auf die oben genannten Felder der deutsch-jugoslawischen Migrationsbeziehungen konnte nur in Kooperation mit dem Aufnahmestaat gelingen, der sich die deutsche Seite jedoch bis zum Regierungswechsel 1966 größtenteils verschloss.

\section{Regelung zwischenstaatlicher Migrationsbeziehungen im Kontext der politischen Annäherung von Brandt und Tito ab 1967}

Neue Impulse bekam das bilaterale Verhältnis zu Jugoslawien sowie die Klärung der noch offenen jugoslawischen „Gastarbeiterfrage“ schließlich durch die neue Regierung der Großen Koalition (CDU/CSU/SPD) sowie durch die Ernennung Willy Brandts zum Bundesaußenminister und Vize-Kanzler im Dezember 1966. ${ }^{45}$ Im Rahmen der neuen Ostpolitik des Außenministers Brandt konnte das blockfreie Jugoslawien als Mitglied der europäischen Staatengemeinschaft aus der bundesdeutschen Politik der Entspannung und Kooperation nicht ausgeklammert werden. ${ }^{46}$ Der 1957 vollzogene Abbruch der diplomatischen Beziehungen sowie die von Jugoslawien geforderten und von bundesdeutscher Seite abgelehnten Entschädigungszahlungen für die jugoslawischen Opfer des Zweiten Weltkriegs waren die

\footnotetext{
${ }^{43}$ AJ 130/626/1034: Državni sekretarijat za inostrane poslove, II uprava, br. 432162; Informacija o najnovijem pogoršanju u odnosima SRN-SFRJ, Beograd, 12.9.1966.

44 AJ 130/626: Državni sekretarijat za inostrane poslove, II uprava, br. 418385; Informacija o poseti Jugoslaviji vice-kancelera i ministra spoljnih poslova SR Nemačke Willy Brandta, od 12. do 14. VI 1968, Beograd, 29.5.1968, Bl.9.

${ }^{45}$ Vladimir Ivanović, Obnavlajnje diplomatskih odnosa između Socijalističke Federativne Republike Jugoslavije i Savezne Republike Nemačke, in: Istorija 20.Veka, 2 (2005), S.136, Anm.22; ders., Jugoslavija i SR Nemačka 1967-1973, Belgrad 2009, S.134-143; vgl. Schönwälder, Einwanderung und ethnische Pluralität, S.343f., 365; Mattes, „Gastarbeiterinnen“ in der Bundesrepublik, S.53; Hadžić, Titos „Gastarbeiter“. Hintergründe und Ursachen, S.103-114; Knortz, Diplomatische Tauschgeschäfte, S.140-152.

${ }^{46}$ Vgl. Akten zur Auswärtigen Politik der Bundesrepublik Deutschland, hrsg. im Auftrag des Auswärtigen Amts vom Institut für Zeitgeschichte (AAPD), Bd.I: 1.Januar bis 31. März 1967, München 1998, Dok. 88, Bundesminister Brandt an Bundeskanzler Kiesinger, 6.3.1967, S.414.
} 
zwei großen Hindernisse, die eine politische Annäherung im Sinne der neuen Entspannungspolitik überwinden musste. Einer Wiederaufnahme der diplomatischen Beziehungen stand Jugoslawien aufgeschlossen gegenüber, ohne dafür offiziell Vorbedingungen zu formulieren. Allerdings erwartete die Regierung Belgrads von der Bundesrepublik für eine „volle Normalisierung“ der Beziehungen „die Befriedigung ihrer Wiedergutmachungs- und Reparationsforderungen, das Verbot ,terroristischer" Emigrantenumtriebe im Bundesgebiet sowie eine vertragliche Regelung des Status der jugoslawischen Gastarbeiter“. ${ }^{47}$

Die Wiederaufnahme der diplomatischen Beziehungen mit einem Land, das die „Sünde“ begangen hatte, die DDR anzuerkennen, gestaltete sich für das Auswärtige Amt schwierig ${ }^{48}$ : Zum einen musste in Zusammenarbeit mit Jugoslawien einer Fehlinterpretation entgegengewirkt werden, die Staaten der „Dritten Welt“ ermutigt hätte, nun ebenfalls diplomatische Beziehungen zu Ostberlin aufnehmen zu wollen. Zum anderen galt es, die jugoslawischen Entschädigungsforderungen aus finanziellen und wirtschaftlichen Gründen abzulehnen, um einen Präzedenzfall zu vermeiden, obwohl die bundesdeutsche Seite wusste, dass Jugoslawien nicht bereit war, die Wiedergutmachungsforderungen ersatzlos fallen zu lassen. Daher stellte sich die Frage, welche Art von Wirtschaftshilfe für Jugoslawien angemessen und für die Bundesrepublik machbar erschien, um auch in Zukunft in einer freundlichen politischen Beziehung zum jugoslawischen Staat die Entschädigungsansprüche abwehren zu können. Willy Brandt schlug daher am 6. März 1967 Bundeskanzler Kurt Georg Kiesinger ein Beamtengespräch in Belgrad vor, um zu klären, was unmittelbar geschehen könnte, um die Beziehungen zwischen den beiden Staaten zu verbessern, und führte unter anderem die Wiederaufnahme der Gespräche über ein „Gastarbeiter“- und Sozialversicherungsabkommen an. ${ }^{49}$ Trotz der widrigen wirtschaftlichen Umstände im Rezessionsjahr 1967 und der Ablehnung eines weiteren Anwerbeabkommens durch das Bundesministerium für Arbeit war für Brandt die Wiederaufnahme der Anwerbegespräche ein wichtiger Berührungspunkt für eine Annäherung mit Jugoslawien. So schrieb der Außenminister noch am 21.April 1967 dem Bundesminister für Arbeit und Sozialordnung, Hans Katzer:

\begin{abstract}
„Wie Sie wissen, ist die Bundesregierung im Rahmen ihrer Ostpolitik bemüht, auch das Verhältnis zu Jugoslawien zu verbessern. Die Fortsetzung der (bereits mehrfach unterbrochenen) deutschjugoslawischen Verhandlungen über ein Anwerbe- und ein Sozialversicherungsabkommen für jugoslawische Arbeiter in Deutschland bietet eine Gelegenheit, diesem Ziel einen Schritt näherzukommen. Die jugoslawische Regierung hat wiederholt zum Ausdruck gebracht, daß sie besonderen Wert auf eine möglichst baldige Wiederaufnahme dieser Verhandlungen legt. Ich würde es deshalb unter außenpolitischen Gesichtspunkten für gut halten, wenn wir dem Wunsch der Jugoslawen möglichst bald entsprechen könnten. Dabei verkenne ich nicht, daß bei der gegenwärtigen Arbeitsmarktlage und im Hinblick auf die anderen Länder, mit denen bereits Anwerbeabkommen geschlossen sind, gewisse Bedenken bestehen, die deutsch-jugoslawischen Verhandlungen gerade jetzt wieder aufzunehmen. Trotzdem glaube ich, daß die für eine Fortsetzung der Verhandlungen sprechenden außenpolitischen Gründe den Vorrang haben sollten. ${ }^{\star 50}$
\end{abstract}

Während der deutsch-jugoslawischen Wirtschaftsverhandlungen vom 24. bis 29. April 1967 in Belgrad drängte die jugoslawische Delegation auf eine Festlegung des Termins für den Abschluss eines Anwerbeabkommens. Der deutschen Seite erschien das jedoch nicht als angemessen, da die Abstimmung zwischen den Ministerien über den Sinn eines An-

\footnotetext{
${ }^{47}$ AAPD, Bd.I: 1.Januar bis 31. März 1967, Dok. 15, Gespräch zwischen Brandt und Couve de Murville, S.85, Anm.33.

${ }^{48}$ Vgl. Zoran Janjetović, Od Auschwitza do Brijuna. Pitanje otštete žrtvama nacizma u jugoslavenskozapadnonjemačkim odnosima, Zagreb 2007.

49 AAPD, Bd.I: 1.Januar bis 31.März 1967, Dok. 88, Bundesminister Brandt an Bundeskanzler Kiesinger, 6.3.1967, S.412f.

${ }^{50}$ BArch, B 149/6241, Bundesminister des Auswärtigen an Bundesminister für Arbeit und Sozialordnung Herrn Hans Katzer, Bonn, 21.4.1967, Bl.1.
} 
werbevertrags noch nicht abgeschlossen worden war. Auf Referentenebene des Auswärtigen Amts, der Innen-, Wirtschafts-, Arbeits-, Finanz- und Vertriebenenministerien konnte keine Einigkeit über die Wiederaufnahme der deutsch-jugoslawischen Anwerbegespräche hergestellt werden. ${ }^{51}$ Die deutsche Delegation sagte den Jugoslawen beschwichtigend zu, sich bei der Bundesregierung für einen baldigen Verhandlungstermin einzusetzen. Botschafter Egon Emmel sah bei einer weiteren Stagnation der deutsch-jugoslawischen „GastarbeiterVerhandlungen“ die Gefahr, dass die „derzeitige jugoslawische Einstellung uns gegenüber schlagartig und erheblich einem neuerlichen Tiefpunkt“ entgegen führen werde. ${ }^{52}$

Neben den positiven Effekten einer bilateralen Regelung der Arbeitsmigration für die deutsch-jugoslawischen politischen Beziehungen und die neue Ostpolitik im Allgemeinen betonte der Bundesaußenminister in einer Kabinettsvorlage vom 5.Juni 1967 auch die wirtschaftlichen Vorteile für die Bundesrepublik:

„Wer aber exportieren will, sollte dem Einfuhrland Möglichkeiten geben, die Importe auch zu bezahlen. [...]. Unter außenwirtschaftlichen Gesichtspunkten sollte daher für die Jugoslawen die Möglichkeit bestehen, im Wirtschaftsverkehr mit uns mit den ihnen zu Gebote stehenden Mitteln, d.h. neben der Warenausfuhr auch durch die Abgabe von Arbeitskräften an uns, mitzuhalten." ${ }^{33}$

Neben dem Finanzminister und dem Minister für Vertriebene lehnte Bundesarbeitsminister Hans Katzer einen Anwerbevertrag mit Jugoslawien angesichts der anhaltenden schwierigen Arbeitsmarktlage ab. Katzer rechtfertigte seine kritische Haltung damit, dass die Zahl der in der Bundesrepublik beschäftigten Jugoslawen auch ohne Anwerbevereinbarung ständig gestiegen sei. Außerdem könnten mit dem Abschluss eines Anwerbevertrages „nicht nur wie bisher - Fachkräfte, sondern auch Hilfsarbeiter angeworben werden“, was unnötig sei. ${ }^{54}$ Mit dem Hinweis auf 460000 Arbeitslose warnte Katzer vor der öffentlichen Kritik an einem neuen Anwerbevertrag: „Es ist bekannt, daß der überwiegende Teil der deutschen Bevölkerung - mehr aus emotionalen als aus rationalen Gründen - gegen eine Beschäftigung von Ausländern eingestellt ist. “55 Zudem befürchtete er die Verstimmung der anderen Anwerbeländer, die sich bereits besorgt gezeigt hätten über den Rückgang der Zahl ihrer Arbeitsmigranten. Ferner würde Italien in dem Abschluss einer deutsch-jugoslawischen Anwerbevereinbarung einen Verstoß gegen den Vorrang des EWG-Arbeitsmarkts gegenüber Drittstaaten sehen.

Die jugoslawische Seite sah die deutsch-jugoslawischen Verhandlungen über ein Anwerbeund Sozialversicherungsabkommen als Probe des guten Willens im Kontext der bilateralen Gespräche um eine Wiederaufnahme der politischen Beziehungen und einer nachhaltigen Kooperation. Schließlich erreichte die jugoslawische Seite im November 1967 der lang ersehnte Vorschlag des Bundesaußenministeriums, die Gespräche über ein Abkommen zur Beschäftigung, Sozialversicherung und Arbeitslosenversicherung wiederaufzunehmen, allerdings unter dem Vorbehalt, dass es zunächst nur um die Anwerbung qualifizierter und weiblicher Arbeitskräfte gehen könne. Die jugoslawische Regierung bestand jedoch

\footnotetext{
${ }^{51}$ Vgl. Knortz, Diplomatische Tauschgeschäfte, S. 146.

${ }^{52}$ AAPD, Bd.II: 1.April bis 31.August 1967, München 1998, Dok. 156, Aufzeichnung des Botschafters Emmel, Bericht über die deutsch-jugoslawischen Wirtschaftsverhandlungen vom 24. bis 29. April 1967 in Belgrad, 3.5.1967, S.702f.

${ }^{53}$ BArch, B 149/6241, Bundesminister des Auswärtigen an Chef des Bundeskanzleramtes, Anlage zur Kabinettssache des Auswärtigen Amtes vom 5.Juni 1967, Betr.: Fortsetzung der Verhandlungen über eine Anwerbevereinbarung und ein Sozialversicherungsabkommen mit Jugoslawien, Bonn, 5.6.1967, B1. 4 .

${ }^{54}$ BArch, B 149/6241, Bundesminister für Arbeit und Sozialordnung an Chef des Bundeskanzleramtes, Bonn, 9.6.1967, Bl.2.

${ }^{55}$ Ebenda, Bl.2f.
} 
bei einer Fortführung der Anwerbegespräche auf der Gleichbehandlung mit anderen Anwerbestaaten. ${ }^{56}$

Dennoch trug die deutsch-jugoslawische Annäherung über die Themen der wirtschaftlichen Zusammenarbeit und eines bilateralen Anwerbeabkommens Früchte. Am 24.Januar 1968 führten Ministerialdirektor Dr. Hans Ruete und der Leiter der jugoslawischen Delegation, Ministerialdirektor Dr. Zvonko Perišić, ein langes Vier-Augen-Gespräch, um alle mit einer Wiederaufnahme der diplomatischen Beziehungen zusammenhängenden Fragen zu erörtern. Dazu zählte auch der Umgang der Bundesrepublik mit politischen Flüchtlingen aus Jugoslawien. Perišić bat mit "großer Betonung erneut darum“, unter politischen Gesichtspunkten diesen „Störfaktor“ auszuschalten. ${ }^{57}$ Die in Jugoslawien seit Jahrzehnten praktizierte Eliminierung politischer Opponenten schien im Migrationskontext an ihre Grenzen zu stoßen, da durch die Rechtsordnung der Bundesrepublik präventiven und repressiven Maßnahmen rechtsstaatliche Grenzen gesetzt waren. Im Entwurf des Verhandlungsauftrags vom Dezember 1967 für den Delegationsleiter der Bundesrepublik hieß es dazu:

„Die Bundesregierung unterstützt keine gegen die Integrität des jugoslawischen Staates gerichtete Bestrebung. Das Recht der freien Meinungsäußerung, das im Grundgesetz auch für Ausländer gewährleistet ist, kann sie allerdings nicht beschneiden. ${ }^{\text {"58 }}$

Im Januar 1968 wurden zunächst die diplomatischen Beziehungen zwischen der Bundesrepublik und Jugoslawien wieder hergestellt. Als sich die Situation auf dem bundesdeutschen Arbeitsmarkt im selben Jahr entspannte, wurden im März 1968 die deutsch-jugoslawischen Anwerbeverhandlungen offiziell wieder aufgenommen. Das Bundesministerium für Arbeit war jedoch immer noch nicht einverstanden, über die Anwerbung ungelernter Arbeitskräfte zu verhandeln. Ebenso blieben die Fragen nach der von der jugoslawischen Delegation geforderten Kindergeldzahlung für den in Jugoslawien lebenden Nachwuchs der Arbeitsmigranten und die Einrichtung eines ständigen jugoslawischen Betreuungsdienstes offen. Es wurde vereinbart, die Anwerbeverhandlungen im September desselben Jahres fortzusetzen.

Brandt unterrichtete die Regierung, dass sich Jugoslawien gegenüber den anderen Anwerbevertragsländern diskriminiert fühlte und warnte Bundeskanzler Kiesinger im Juni 1968 vor einer Stagnation der Anwerbeverhandlungen:

„Wenn wir bei der für September vorgesehenen Fortsetzung der Verhandlungen mit Jugoslawien weiter auf unserem Standpunkt beharren, ist zu befürchten, dass die Gesamtverhandlungen scheitern werden. Dies würde einen Rückschlag in der Entwicklung der deutsch-jugoslawischen Beziehungen bedeuten und damit die gesamte Ostpolitik ungünstig beeinflussen. ${ }^{599}$

Bei einem Besuch Brandts in Jugoslawien vom 12. bis 14.Juni 1968 griff Tito wieder das Thema der politischen Flüchtlinge auf. Er argumentierte, dass „faschistische Elemente von Deutschland aus Unruhe stifteten" und damit die Stimmung der jugoslawischen Bevölkerung beeinflussten.$^{60}$ Brandt wies darauf hin, dass die Sicherheitsbehörden der beiden Länder gemeinsam bemüht seien, dieses Problem unter Kontrolle zu halten. ${ }^{61}$ Auch der jugoslawische Außenminister Nikezić bestätigte, dass die Zusammenarbeit zur Verhinderung der Terrortätigkeit von Emigranten-Organisationen beträchtlich verbessert worden sei ${ }^{62}$

\footnotetext{
${ }^{56}$ Vgl. AJ 130/626: Savezno Izvršno Veče Saveznom Savezu za rad, br. 39/67, Beograd, 2.12.1967.

${ }^{5}$ AAPD, Bd.I: 1.Januar bis 30.Juni 1968, München 1999, Dok. 30, Ministerialdirektor Ruete, z. Z. Paris, an Bundesminister Brandt, 25.1.1968, S.93.

${ }^{58}$ Ebenda, S.93, Anm.12.

${ }^{59}$ Ebenda, Ruete an Auswärtiges Amt, 13.6.1968, Dok. 190, S.717, Anm.8.

${ }^{60}$ Ebenda, Ministerialdirektor Ruete, z. Z. Belgrad, an Auswärtiges Amt, 15.6.1968, Dok. 194, S.734.

${ }^{61}$ Willy Brandt, Begegnungen und Einsichten. Die Jahre 1960-1975, Hamburg 1976, S.232f.

${ }^{6}$ AAPD, Bd.I: 1.Januar bis 30.Juni 1968, Dok. 190, Ministerialdirektor Ruete, z.Z. Belgrad, an Auswärtiges Amt, 13.6.1968, S.718.
} 
Der Beschluss des Bundeskabinetts am 31.Juli 1968, auch männliche jugoslawische Hilfskräfte in die Anwerbevereinbarung mit einzubeziehen und Kindergeld in Höhe der jugoslawischen Leistungen zu gewähren ${ }^{63}$, läutete die Schlussphase der deutsch-jugoslawischen Anwerbegespräche ein. Die im März noch unbeantwortet gebliebenen Fragen wurden schließlich bei den nachfolgenden Verhandlungen vom 7. bis 12. Oktober 1968 geklärt. Die jugoslawische Seite verzichtete auf die Entsendung eines eigenen Betreuungsdienstes, erhielt jedoch das Recht, von Zeit zu Zeit Beauftragte nach Deutschland zu entsenden. Um die jugoslawischen Arbeitnehmer in Deutschland besser betreuen zu können, wurde eine Ausweitung des jugoslawischen Konsulardienstes vereinbart. Ferner wurde entschieden, dass die deutsche Bundesanstalt für Arbeit die Kosten für ihr in Jugoslawien tätiges Personal, für die Räume und Einrichtungsgegenstände selbst tragen sollte. Auch die vollständigen Kosten der medizinischen Untersuchungen, der Sonderzugreisen jugoslawischer Arbeitnehmer in die Bundesrepublik einschließlich Reiseverpflegung wurden von deutscher Seite übernommen. Zudem wurde den jugoslawischen Arbeitnehmern in der Bundesrepublik das für ausländische Arbeitnehmer übliche Kindergeld zugestanden allerdings mit der Einschränkung, dass die Kindergeldregelung des Abkommens automatisch außer Kraft trat, wenn zwei der bereits bestehenden Abkommen im Sinne einer Einschränkung der Kindergeldzahlung geändert wurden. ${ }^{64}$ Des Weiteren wurde ein Abkommen über eine Arbeitslosenversicherung abgeschlossen.

Die von der jugoslawischen Regierung erwarteten positiven wirtschaftlichen Effekte des staatlich organisierten Arbeitskräftetransfers stellten sich für die Volkswirtschaft Jugoslawiens rasch ein. Der Anstieg der Arbeitsmigration in die Bundesrepublik führte zu einer immensen Entlastung des jugoslawischen Arbeitsmarkts. Außerdem entwickelten sich die Devisenüberweisungen der Arbeitsmigranten im Ausland ab 1968 zu einem bedeutenden und stabilen Posten im Nationaleinkommen. Sie wuchsen im Zeitraum von 1968 bis 1976 im Jahresdurchschnitt um etwa 36 Prozent und im Jahr 1976 übertrafen sie die Deviseneinnahmen aus dem Tourismus sogar um das Doppelte. ${ }^{65}$ Die hohen Rücküberweisungen der Arbeitsmigranten aus der Bundesrepublik (Schaubild 2) nach Jugoslawien entwickelten sich zu einer wichtigen Devisenquelle für die Finanzierung des permanent defizitären Handels mit der Bundesrepublik, dem wichtigsten Handelspartner Jugoslawiens. 1974 schätzte „Der Spiegel“ die Höhe der Bankeinlagen der „Gastarbeiter“ in der Bundesrepublik auf rund vier Milliarden DM, „die Bonn auf Umwegen als zinsvergünstigte Kredite den Jugoslawen andienen soll“" ${ }^{66}$ Mit hohen Zinsangeboten von 6 bis 10 Prozent versuchten in der Bundesrepublik eröffnete Handelsfilialen von jugoslawischen Banken an das Gesparte der Arbeitsmigranten zu gelangen. Im Jahr 1975 bemerkte Bundesaußenminister HansDietrich Genscher im Gespräch mit dem jugoslawischen Bundesminister Miloš Minić, dass, wenn sein Amt ihn nicht daran hindern würde, er die Gründung einer „GenscherMinić Bank“ vorgeschlagen hätte. ${ }^{67}$

\footnotetext{
${ }^{63}$ BArch, B 149/22399, Abt. II, IIa5 - 2430.6 - 208/68, Deutsch-jugoslawische Verhandlungen über den Abschluss einer Anwerbevereinbarung, eines Abkommens über soziale Sicherheit einschließlich des Kindergeldes und eines Abkommens über Arbeitslosenversicherung, Bonn, 18.10.1968.

${ }^{64}$ Ebenda.

${ }^{65}$ Künne, Die Außenwanderung, S.183-185.

66 Tito bei den Deutschen, in: Der Spiegel, 24.6.1974.

${ }^{67}$ AAPD, Bd.II: 1.Juli bis 31.Dezember 1975, Dok. 330, Gespräch zwischen Genscher und Minić, 4.11. 1975, S. 1540.
} 
Schaubild 2: Geldtransfers der Arbeitsmigranten aus der Bundesrepublik nach Jugoslawien von 1961 bis 1973 in Millionen DM

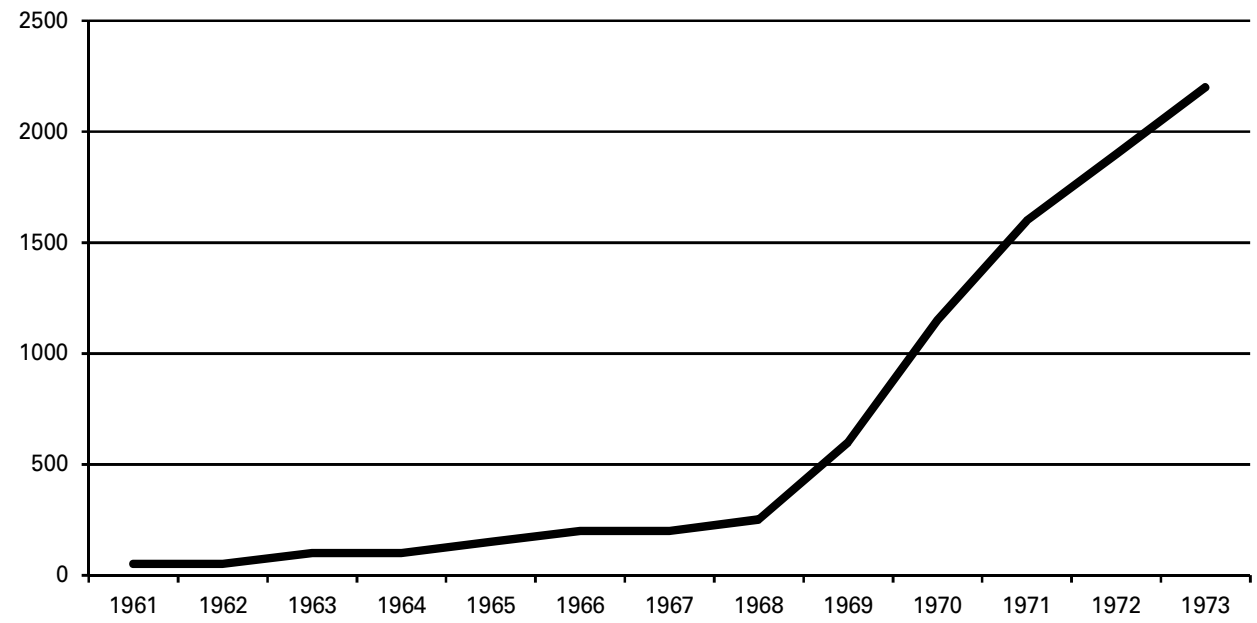

Quelle: Monatsbericht der Deutschen Bundesbank, 26.Jg., Nr.4, April 1974, S. 23.

Die staatlichen Betreuungsdienste, aber auch die politische Überwachung der Arbeitsmigranten durch den jugoslawischen Staat auf bundesdeutschem Gebiet erfolgte durch die Aufstockung des diplomatischen Apparats, wobei die Verlängerung oder Nichtverlängerung des Reisepasses die wirksamste Kontrollmöglichkeit bot. ${ }^{68}$ Während es 1969 im Bundesgebiet erst zwei Generalkonsulate (München, Hamburg) gab, wurden in den Folgejahren bis 1972 zehn weitere eröffnet.

Auch die deutsch-jugoslawische Zusammenarbeit im Hinblick auf die Überwachung und Verhinderung der Tätigkeit der politischen Gegner auf dem Gebiet der Bundesrepublik funktionierte im Sinne der von Jugoslawien angestrebten „Ausschaltung des Störfaktors“. Seit dem bundesdeutschen Vereinsgesetz von 1964 wurden elf ausländische Gruppen vom Bundesinnenminister verboten, davon zwischen 1968 und 1976 vier kroatische rechtsextremistische Organisationen: der Kroatische Demokratische Ausschuss, die Kroatische Revolutionäre Bruderschaft, der Kroatische Nationale Widerstand und der Kroatische Verein Drina. ${ }^{69}$

Außerdem wurde der jugoslawische Geheimdienst auf bundesdeutschem Gebiet aktiv und begann, feindliche Personen und Emigrantenorganisationen durch „Desinformations- und Rufmordkampagnen bis hin zur Liquidierung von missliebigen Personen“ zu "passivieren“.70 So stellte im Jahr 2008 das Oberlandesgericht München in einem Strafverfahren gegen einen ehemaligen jugoslawischen Geheimdienstmitarbeiter wegen des im Jahr 1983 begangenen Mordes an dem kroatischen Emigranten Stjepan Đurekovic ${ }^{71}$ fest, dass die Sicherheitsdienste der Teilrepubliken eine Abteilung eingerichtet hatten, deren Aufgabe es war, im Ausland

\footnotetext{
${ }^{68}$ Klaus Manfrass, Die Beziehungen zwischen der Bundesrepublik und den einzelnen Herkunftsländern im Zeichen der Arbeitskräftewanderung, in: Lohrmann/Manfrass (Hrsg.), Ausländerbeschäftigung, S.255-334, hier S. 286.

${ }^{69}$ Steffen Kailitz, Politischer Extremismus in der Bundesrepublik Deutschland. Eine Einführung, Wiesbaden 2004, S.219.

70 Oberlandesgericht München: Urteil des 6.Strafsenates des Oberlandesgerichts München im Strafverfahren gegen P. wegen Mordes aufgrund der am 13. Februar 2008 begonnenen Hauptverhandlung in der öffentlichen Sitzung am 16.Juli 2008, Aktenzeichen: 6 St 005/05 (2), S. 10.

${ }^{71}$ Andreas Wassermann, Titos geheime Mörder, in: Der Spiegel, 6.12.2010, S.54f.
} 
gegen politische Flüchtlinge vorzugehen: „Der Senat ist [...] überzeugt, dass politische Funktionsträger in Jugoslawien Mordaufträge erteilten, die auf dem Boden der Bundesrepublik Deutschland ausgeführt wurden“. ${ }^{72}$ Zwischen 1970 und 1989 wurden 22 Tötungsdelikte gegen kroatische Exilanten in der Bundesrepublik Deutschland begangen, die ausschließlich politisch motiviert waren, konstatiert das Oberlandesgericht München. ${ }^{73}$ Die Aktivitäten des jugoslawischen Geheimdienstes in der Bundesrepublik waren allerdings auch damals schon bekannt. Bereits 1982 berichtete „Der Spiegel“ über die blutigen Auseinandersetzungen zwischen jugoslawischen Geheimdienstlern und Regimegegnern auf deutschem Boden und stellte im Hinblick auf die geringe Aufklärungsrate fest: „Politische Unterstützung beim Kampf gegen den jugoslawischen Untergrundkrieg finden die Polizeistellen kaum. “74

Heike Knortz sieht im Engagement des bundesdeutschen Außenministeriums für den deutsch-jugoslawischen Anwerbevertrag ihre These des Primates der Außenpolitik auf dem Feld der Arbeitsmigration bestätigt. ${ }^{75}$ Auch Karen Schönwälder konstatiert, dass der Anwerbevertrag mit Jugoslawien von Außenminister Brandt im Interesse der neuen Ostpolitik durchgesetzt wurde. ${ }^{76}$ Jedoch wäre es zu kurz gegriffen, das deutsch-jugoslawische Anwerbeabkommen auf ein Mittel oder Interesse der bundesdeutschen Ostpolitik zu reduzieren, da somit die Rolle des Vertragspartners und sein Interesse am Abschluss des Abkommens ausgeblendet wird. Die neue Ostpolitik wandte sich schließlich an einen potentiellen Partner, in diesem Falle Jugoslawien, der an eine zwischenstaatliche Kooperation seine eigenen Bedingungen stellte. Sicherlich war die neue bundesdeutsche Ostpolitik ein Türöffner für die von der jugoslawischen Seite lang ersehnte Wiederaufnahme der Anwerbegespräche, jedoch spielten auch im Vorfeld der Anwerbegespräche die wirtschaftlichen Abhängigkeiten, die Tito auf seinem sozialistischen Sonderweg mit der Bundesrepublik eingegangen war, und die Gefahr der innenpolitischen Destabilisierung Jugoslawiens durch politisch aktive Emigranten sowie die hohe Anzahl und Nachfrage nach jugoslawischen Arbeitnehmern in der Bundesrepublik eine wichtige Rolle in der durch das Abkommen institutionalisierten zwischenstaatlichen Zusammenarbeit im Feld der Arbeitsmigration.

Als am 12. Oktober 1968 das deutsch-jugoslawische Anwerbeabkommen unterzeichnet wurde, war in beiden Ländern keine Rede von einer dauerhaften Einwanderung respektive Auswanderung der jugoslawischen Arbeitskräfte nach Deutschland. Zwar wurden in den folgenden Jahren der Arbeitskräftetransfer von Jugoslawien nach Deutschland oder die Urlaubsaufenthalte der Deutschen in Jugoslawien auch im Lichte der Völkerverständigung und des kulturellen Austausches gesehen, doch hielten die Regierungen des Aufnahmeund Entsendelandes in ihrer politischen Rhetorik über Jahrzehnte an dem Konzept der „Zeitweiligkeit“ des Aufenthaltes der Arbeitsmigranten fest. Mit der Zeit übernahmen sogar die Sprachen des ehemaligen Jugoslawiens das aus dem Deutschen abgeleitete Wort „gastarbajter/гастарбајтер“ als Bezeichnung für Menschen, die im Ausland arbeiten und ihren Urlaub in der „alten Heimat“ verbringen. Der politische Grundsatz „Deutschland ist kein Einwanderungsland“ als Leitlinie der deutschen Migrationspolitik ${ }^{77}$ fand seine Entsprechung in der jugoslawischen Leitlinie des „temporären Arbeitsaufenthalts der jugoslawischen Arbeiterklasse im Ausland“. Damit steuerte die Politik beider Länder mit Scheuklappen an den Lebenswirklichkeiten der Arbeitsmigranten vorbei.

\footnotetext{
72 Oberlandesgericht München: Urteil, S. 10, 82.

${ }^{73}$ Ebenda, S. 15.

${ }^{74}$ Das ganze sieht nach Hinrichtung aus, in: Der Spiegel, 25.1.1982, S.54.

75 Knortz, Diplomatische Tauschgeschäfte, S. 140-152.

76 Schönwälder, Einwanderung und ethnische Pluralität, S.365.

${ }^{77}$ Friedrich Heckmann, 50 Jahre Integrationspolitik in Deutschland?, efms paper 5 (2010), S.5, unter http:/ /www.efms.uni-bamberg.de/pdf/efms\%20paper\%202010-5.pdf (12.1.2011).
} 